\title{
Digital Process and Materials 2014-Where Are You?
}

Author

DANIEL J. POTICNY, DDS*

\section{Associate Editor}

EDWARD J. SWIFT JR., DMD, MS
Computer-aided design/computer-aided manufacturing (CAD/CAM) is no longer a risky economic or clinical decision if your practice is focused on reducing the use of metals and dedicated to a better patient experience. Although metal-based restorations have a proven track record, their use is greatly diminishing owing to the high cost of precious metals, allergies to base metals, and general dissatisfaction with esthetics. Tooth-colored dental materials for fixed prosthodontics have rapidly evolved and are constantly improving. With materials such as alumina, zirconia, lithium silicates, and adhesively bonded esthetic glass and polymer ceramics, our portfolio of restorative options is expanding to the point where confusion and lack of knowledge is becoming evident, primarily due to their association with digital processing.

All of these ceramics are machined in monolithic form and in nearly all cases are digitally designed, which means that they are only possible through the CAD/CAM process. You are in fact a "CAD/CAM dentist" if you use any of these materials even without owning the hardware associated with their use. As clinicians, we demand the best for our patients using form, fit, function, and esthetics as the criteria. Contemporary monolithic materials can be digitally designed, milled, and characterized to satisfy all of the aforementioned criteria to an extent comparable with that of well-made conventional lab ceramics.

Monolithic materials are chip-resistant, easily handled, and consistent due to industrial fabrication in a form from which a restoration will eventually emerge, making them ideal for the posterior regions of the mouth. Anterior restorations still require hand layering for optimal esthetics, but many laboratory technicians state they are very comfortable with this concept and expect it to become the new norm-yes, this is the maturation of the CAD/CAM process (Figures 1 and 2).

The material "tail" is now "wagging the dog," and we the dentists are the dog! The concepts and devices for CAD/CAM were originated as early as 1973 (Duret) ${ }^{1,2}$ and brought to fruition in 1985 with CEREC (Mörmann and Brandestini) $)^{3-5}$ with the use of a single feldspathic ceramic (Vita MK II, Vident, Brea, CA, USA) that has achieved a nearly 30-year record of clinical success. We now have many choices for both systems and materials. Accuracy and fit are the equal or better of the lab with successful long-term outcomes reported both anecdotally and in the scientific literature. CAD/CAM is now early mainstream owing to 28 years of innovation in process and materials.

After lagging CAD/CAM dentists for many years, laboratories are now far ahead of us in the CAD/CAM environment with many of them entering the late stages of mainstream representation for this process. Nearly one third of US dental labs over the last 10 years have been lost with rapid, large-scale consolidation among the remaining labs, yet dentists today are still demanding more (better) for less (cost). Labs large and small now routinely use scanning and digital design, allowing them to greatly multiply their production with consistent quality at lower and more stable price points. Digital processing also removes the tedium associated with traditional fabrication methods, allowing for a new

*Daniel J. Poticny, DDS, Dallas, TX, USA; Adjunct Clinical Associate Professor, Department of Cariology, Restorative Sciences and Endodontics, University of Michigan School of Dentistry, Ann Arbor, MI, USA 


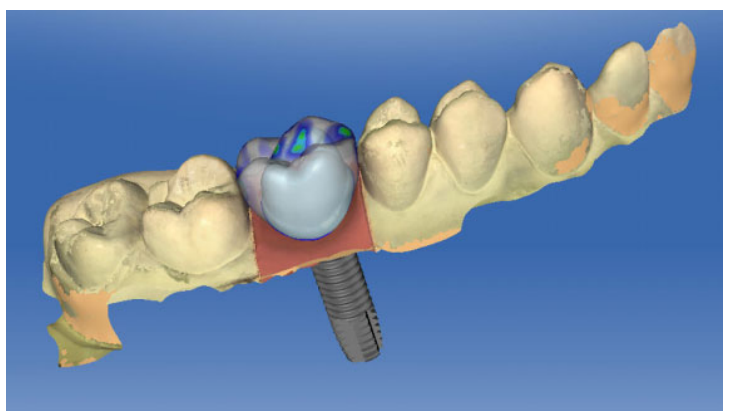

FIGURE I. Virtual simultaneous fabrication of abutment and crown with no model for chairside production and delivery CEREC Omnicam (Sirona Dental).

breed of lab technicians who are younger and more inclined to understand and use digital processes that will revitalize a necessary but aging industry. All of this has created new economies of scale to which dentists must adapt.

You can be highly competent as an "analog" dentist using impression materials and stone models-but why supply your digital lab with dimensionally unstable, environmentally unfriendly, labor-intensive objects that $90 \%$ of the time are unnecessary? Do you know that using a digital scan file sent over the Internet with digital design for a single crown (most common lab procedure today) eliminates the need for a solid model in most cases? For chairside CAD/CAM dentists or in the digital lab, abutments and crowns can be done virtually-with no model at all (Figure 1). A digital impression can be stored in the cloud indefinitely with a model printed on demand if and when needed. Can you appreciate the beauty of this experience for you and your patient? The labs are the second "tail wagging us dogs" and the labs now need us to close this open loop.

Closing this loop does not need to involve milling a restoration at the chair, although in-office milling does avoid the "open wound" of a provisional and permits more conservative "defect-oriented treatment" using adhesive concepts that minimize the need for preparation forms to hold temps in place. Regardless, chairside CAD/CAM is not an appropriate fit for everyone, and it will always be a personal choice.

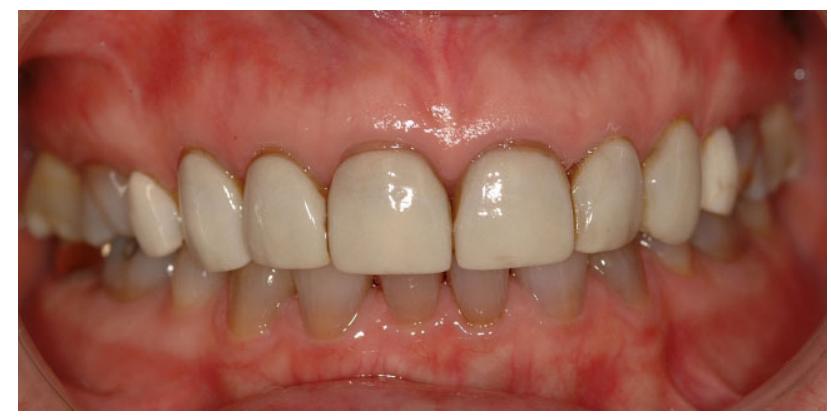

FIGURE 2. Pre-operative condition of 20-year-old feldspathic veneers teeth nos. 5-12.

On the other hand, today's reality is this: if you own a digital filmless camera, why not one for the mouth eliminating the film (impression) for it? Labs can partner with you in ways not possible 5 years ago. Where 10 years ago, we had just one; today, there exist numerous devices that can accurately record intraoral structures, closing this loop for nearly all of our fixed cases, orthodontics, implants, and removable devices. Most are at price points lower than that for digital radiography today but with much better economic return. Does anyone remember the $\$ 38,000$ FujiCam intraoral camera? You get my point.

These intraoral scanners are being designed to let them serve as the "digital back office hub" allowing you to compare model sets taken over time, function as intraoral cameras, and produce common STereoLithography file format that can be used by any lab for anything or shared with any clinician across a variety of software platforms. "Apps" are being designed for systems that will allow you to interface with current and emerging technologies. Others platforms will allow you to add chairside manufacture to the digital scanner should you later decide it is a fit for your practice. Outcomes for digital impressions, materials, and process using printed models are comparable with conventional methods with less effort and far more flexibility in terms of handling, transportation, storage, disinfection, and privacy (Figures 2-4).

"Riding the pine" (as we used to say in sports) for too long in dentistry, in what is now a nearly mature 


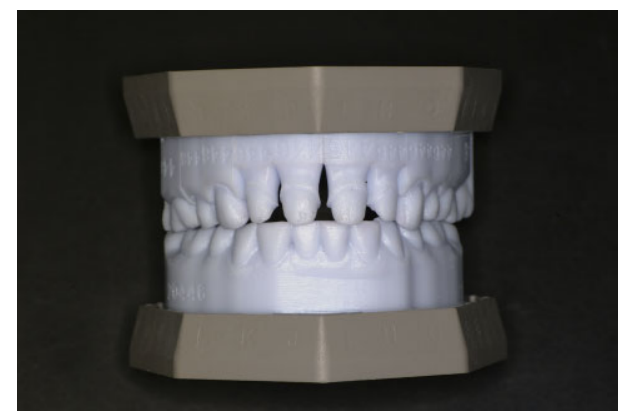

FIGURE 3. Stereo lithographic model fabricated through additive manufacturing (SLA model) printed from digital scan for fabrication of crowns and veneers.

technology environment, comes at the cost of diminished financial and professional returns to you and benefit to your patient. I would submit that if you have not acted yet, 2014 is your opportunity to at least consider the benefits of digital processing. Explore your possibilities now; time is no longer your friend; it's time to get off the bench!

\section{REFERENCES}

1. Wittneben JG, Wright RF, Weber HP, Gallucci GO. A systematic review of the clinical performance of CAD/CAM single-tooth restorations. Int J Prosthodont 2009;22:466-71.

2. de Divonne A-C. An interview with Dr. François Duret. Reprinted in Inside Dental Technology 2013; 4(3) from Clinic, Journal of Dentistry-a publication of Wolters Kluwer France. Available at: http://www.dentalaegis.com/ idt/2013/03/an-interview-with-dr-francois-duret (accessed April 15, 2014).

3. Allen KL, Schenkel AB, Estafan D. An overview of the CEREC 3D CAD/CAM system. Gen Dent 2004;52:234-5.

4. Mörmann WH, Bindl A. The new creativity in ceramic restorations: dental CAD-CIM. Quintessence Int 1996;27:821-8.

5. Mörmann WH. The evolution of the CEREC system. J Am Dent Assoc 2006;137(Suppl 1):7S-13S.

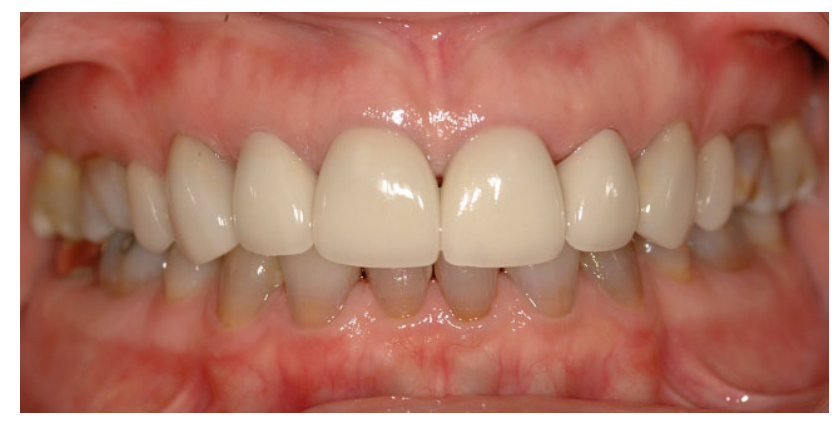

FIGURE 4. Lava (3M ESPE, St. Paul, MN, USA) veneered zirconia crowns \#7-10 and e.max CAD (Ivoclar Vivadent, Amherst, NY, USA) labial veneers \#5, 6, II, 12 immediately post-insertion.

\section{SUGGESTED READING}

Ender A, Mehl A. Full arch scans: conventional versus digital impressions-an in-vitro study. Int J Comput Dent 2011;14:11-21.

Fasbinder DJ. The CEREC system: 25 years of chairside CAD/CAM dentistry. J Am Dent Assoc 2010;141(Suppl 2):3S-4S.

Fasbinder DJ. Computerized technology for restorative dentistry. Am J Dent 2013;26:115-20.

Poticny DJ, Klim J. CAD/CAM in-office technology: innovations after 25 years for predictable, esthetic outcomes. J Am Dent Assoc 2010;141(Suppl 2):5S-9S.

Zimmer S, Göhlich O, Rüttermann S, Lang H, Raab WH, Barthel CR. Long-term survival of Cerec restorations: a 10-year study. Oper Dent 2008;33:484-7.

Contemporary Issues

Daniel J. Poticny

Department of Cariology, Restorative Sciences and Endodontics

Computerized Dentistry Graduate Program

University of Michigan School of Dentistry

Ann Arbor, MI, USA

Telephone: 972-641-9888

E-mail: dfwdds@umich.edu 